\title{
Barriers and facilitators to switching from smoking to vaping: Advice from vapers
}

\section{Running title: Advice from vapers on switching to vaping}

Kylie Morphett ${ }^{1}$, Megan Weier ${ }^{2,3}$, Ron Borland ${ }^{4}$, Hua-Hie Yong ${ }^{5,6}$ and Coral Gartner ${ }^{1}$

1. Faculty of Medicine, School of Public Health, The University of Queensland, Brisbane, Australia

2. Centre for Social Impact, University of New South Wales, Sydney, Australia

3. Centre for Youth Substance Abuse Research, The University of Queensland, Brisbane, Australia

4. Cancer Prevention, Cancer Council Victoria, Melbourne, Australia

5. Nigel Gray Fellowship Group, Cancer Council Victoria, Melbourne, Australia

6. School of Psychology, Deakin University, Melbourne, Australia

Kylie Morphett PhD, Research Fellow, Megan Weier PhD, Research Associate and Honorary Research Fellow, Ron Borland PhD, Nigel Gray Distinguished Fellow, Hua-Hie Yong PhD, Senior Research Associate and Associate Professor, Coral Gartner PhD, Principal Research Fellow.

* Author to whom correspondence should be addressed; Dr Kylie Morphett, University of Queensland School of Public Health, Public Health Building, Corner of Wyndham Street and Herston Road, Herston, Qld 4029, Australia. E-Mail: k.morphett@uq.edu.au; Tel: $+61-(0) 7-3346-5475$.

This is the author manuscript accepted for publication and has undergone full peer review but has not been through the copyediting, typesetting, pagination and proofreading process, which may lead to differences between this version and the Version of Record. Please cite this article as doi: $10.1111 /$ dar.12907

This article is protected by copyright. All rights reserved. 
Advice from vapers on switching to vaping

Conflicts of interest: None to declare.

This article is protected by copyright. All rights reserved. 


\begin{abstract}
Introduction: Information available to consumers about nicotine vaping products varies according to the regulatory environment. A common information source in Australia, where nicotine vaping products are highly regulated, is advice from vapers. We report on what advice current vapers would give to someone new to vaping. Methods: Australian vapers were recruited in 2016 via the International Tobacco Control Four-Country Smoking and Vaping survey of smokers and ex-smokers, as well as a separate recruitment process that targeted vapers. A total of 384 of 559 eligible participants responded to an open-ended question about barriers to switching from smoking to vaping, and what advice they would give to new vapers. Results: While some participants reported switching from smoking to vaping easily, others described an adjustment period. Difficulties included learning about technical aspects of nicotine vaping products, finding the "right" combination of device and liquid, and accessing nicotine liquid given that it cannot legally be sold. Many accounts of satisfaction with quitting smoking and improved health were provided. Discussion: Advice from current vapers is likely to be particularly influential in Australia, where information about vaping is not easily available from health organisations or official government sources. This research shows that advice to new vapers centres around experimentation with devices and flavours and finding trustworthy suppliers of nicotine liquid. It provides an insight into the initial challenges associated with switching from smoking to nicotine vaping products in environments where access to nicotine liquid is highly restricted.
\end{abstract}

Keywords: Electronic cigarettes, smoking cessation, smoking, nicotine, vaping. 
Advice from vapers on switching to vaping

This article is protected by copyright. All rights reserved. 
Advice from vapers on switching to vaping

\section{Introduction}

E-cigarettes, also known as nicotine vaping products (NVP), have become a popular option for smoking cessation in countries where they are easily accessible. In the UK, where NVPs are regulated as consumer products, more people are now using NVPs (known as "vaping") than nicotine replacement therapy [1]. In Australia, most states allow nicotine-free vaping products to be sold and used, but there are few legal options for obtaining the nicotinecontaining vaping products [2].

In Australia, nicotine-containing e-liquid is regulated via the national medicines and poisons regulator, the Therapeutic Goods Association. The Therapeutic Goods Association classifies nicotine as a Schedule 7 "dangerous poison" unless it is in a smoked tobacco product, or if it has been approved for therapeutic use, or is in preparations for animal treatment. No NVPs have been approved for therapeutic use in Australia, therefore none are currently permitted to be sold [3]. The Therapeutic Goods Association does allow importation for personal use if the individual importer has a medical prescription. Prescriptions can also be filled by a pharmacist if the nicotine solution is compounded extemporaneously for the patient, but it is unknown how many pharmacists would perform this service and most pharmacists would not routinely stock the nicotine needed to mix up the preparation. Nevertheless, many Australians vape, with national survey data indicating that $31 \%$ of smokers have ever used vaping product, although it is unclear how many of those are using nicotine-containing vaping products [4]. 
Advice from vapers on switching to vaping

Clinical trial evidence on the effectiveness of NVPs as cessation aids has been limited, but suggests positive effects, albeit not clearly greater than for other nicotine products [5]. Emerging evidence from real world studies suggests that NVPs can assist smokers to quit but their effectiveness is likely dependent on the type of device used, use frequency, and regulatory environment [6-9].

While there is continuing debate about the ultimate health impacts of long-term vaping, there is a developing consensus that for those who are already smoking, switching to vaping will substantially reduce health risk $[10,11]$. NVPs may be more acceptable as long-term substitutes for cigarettes because they deliver nicotine more effectively than nicotine replacement therapy and replicate the hand to mouth action, and sensation, of smoking [12, 13].

Information available to consumers about NVPs varies according to the regulatory environment. In the UK, retailers provide information about selection and safe use of vaping equipment. While public health agencies have encouraged smokers to switch to vaping for health reasons [14], advertising regulations currently prevent retailers and manufacturers from making health or cessation claims about vaping [15]. Because many smokers are misinformed or confused about the safety of NVPs [16], and those selling these products are unable to legally provide advice on these topics, the personal accounts of those who have successfully quit smoking using NVPs are likely to be particularly influential to prospective 
Advice from vapers on switching to vaping

vapers. A recent study highlighted the role of peers (i.e. other vapers) as a source of advice about switching from smoking to vaping [17].

In Australia, where advertising and promotion of NVPs is banned in many states and prominent health organisations discourage smokers from switching to vaping [18], vapers are likely to be the most important source of advice for smokers who want to switch to vaping. However, it is currently unknown what advice experienced NVP users in Australia are providing to those seeking out such information. This paper reports on qualitative data from current Australian vapers on the advice they would give to new vapers. It also examines participant accounts of what has helped them to successfully switch from smoking to vaping, and what the barriers to quitting smoking using this method in Australia were.

\section{Method}

\section{Participants}

The data used for this analysis was gathered from two sources: (i) A cohort of Australian current vapers recruited as an additional component of the International Tobacco Control Four Country Smoking and Vaping (ITC-4CV) Survey; and (ii) Daily vapers from a general sample of Australian smokers and ex-smokers as part of the main ITC-4CV survey recruited by a social research company. Further details about recruitment and the sampling strategy for the ITC survey is reported elsewhere [19]. A number of recruitment methods were used for the dedicated vaper specific sample, including flyers distributed by retailers, posting study information on online vaping forums, and online advertising via social media (Facebook, 
Twitter). Those recruited from both sources responded to the same questions about their use of NVPs. The survey was administered online and data was collected between August and November 2016. Ethics approval for this project was granted by Cancer Council Victoria.

The overall aim of the survey was to explore how and why NVPs are used in Australia. As a final survey item, respondents were asked: "Are there any other comments you would like to make? In particular, we are interested in anything else you can tell us about the main difficulties you had to overcome in switching from smoking to vaping. Include any tips you would give to new vapers." Respondents provided open-ended responses to this question, and were directed to enter "None" if they did not have comments to make. This item was included in the ITC-4CV survey (Wave 1) for the main sample, as well as the sample of vapers recruited via alternative means. Authors RB, HY and CG were all involved in the development of survey items.

\section{Analysis}

Responses were analysed using thematic analysis [20]. MW and KM read all responses several times to establish familiarity, particularly attending to responses that were framed as advice to new vapers. The analysis was guided by the initial research aims, but emergent themes were also identified, thus our approach combined an inductive and deductive approach. Initial codes were generated for each response and these codes were refined over multiple readings and grouped into themes. MW and KM completed independent coding of the results, before the themes were collated and combined. Ideas and opinions on the 
Advice from vapers on switching to vaping

regulation of NVPs in Australia are discussed where relevant, but are not the focus of this analysis.

\section{Results}

\section{Participants}

A total of 559 current daily vapers ( $28 \%$ female; mean age 43 , SD 12$)$ were invited to provide comments in an open text field: 512 from a dedicated sample of vapers, and 47 from daily vapers in the broadly representative population sample. Sixty nine percent of eligible participants $(\mathrm{N}=384)$ submitted responses (358 from the vaper sample and 26 from the general sample) (Table 1), ranging from one sentence to several paragraphs. Of those who submitted responses, 26\% were female and the mean age was 43 (SD 12). Most were selfreported ex-smokers, with 93\% reporting having quit smoking. Also, most were experienced vapers, with approximately $90 \%$ having vaped for three months or longer. The majority (81\%) reported using third generation tank style NVPs. Almost all respondents had used nicotine containing vaping products at some point (99\%). At the time of the survey, $4 \%$ were using non-nicotine liquids, 37\% were using NVPs with nicotine concentrations from 1-4 $\mathrm{mg} / \mathrm{ml}, 27 \%$ using $5-8 \mathrm{mg} / \mathrm{ml}, 20 \%$ using $9-14 \mathrm{mg} / \mathrm{ml}$ and $12 \%$ using $15 \mathrm{mg} / \mathrm{ml}$ or more. The majority (93\%) spoke English only at home, and 2\% identified as Aboriginal or Torres Strait Islander. Approximately $37 \%$ of participants reported some university education.

This article is protected by copyright. All rights reserved. 
Advice from vapers on switching to vaping

Four primary themes were identified in the advice that current vapers gave to prospective vapers. These were labelled: (i) "Do your research"; (ii) Selecting the "right" product; (iii) Acknowledging an adjustment period; and (iv) Benefits of vaping.

\section{"Do your research": Information gathering and barriers to knowledge}

One of the most common pieces of advice for new vapers was that they "do their research" prior to purchasing and experimenting with vaping. Vaping was often portrayed as a technical task, and this was seen as a potential barrier to beginning to vape. Before trying vaping products, an individual needed to decide the following: what type of device to choose; where to buy it from; whether to purchase nicotine, and if so, at what concentration, sort out any legal issues regarding purchase and determine how to obtain ongoing supplies; what type of flavour/s to try; and how to set up and use their device safely.

"New vapers need a lot of help switching from cigs to vaping, face to face is a very important way to help teach someone wanting to switch to vaping from smoking. The endless combinations of $P G / V G$ ratios, nicotine strength, flavors, types of vaping equipment, battery safety and so on makes it very hard for someone wanting to transition from smoking to vaping."

Lack of information because of Australia's restrictive regulatory environment contributed to the difficulty of transitioning to vaping, or conversely, being overwhelmed by the amount of information on the internet. This was compared to the simplicity of smoking cigarettes, which are more accessible and have no technical hurdles.

This article is protected by copyright. All rights reserved. 
Advice from vapers on switching to vaping

“With cigarettes you don't need to know anything except to flick a lighter and inhale.

With vaping, there are a myriad of styles, sizes, wattages, juices - and no general consensus on any of it."

\section{Trusted sources of information}

Many respondents advocated that smokers should source information from vaping stores, websites, or vaping forums, including YouTube, Reddit, and local Australian internet forums such as AussieVapers and Vaper Café Australia. Firsthand knowledge from vapers or from vape stores was frequently described as the best way to obtain the knowledge needed to get started.

"There is good and bad information out there. Do you [sic] own research and perhaps join a forum or speak to a local vape store. I'd stay away from most if not all tobacco shops, even if they sell vape gear as their information may be limited. Youtube can also be a great source of information as well. The best approach would be to go to a vape related meet or talk to a friend who vapes for info."

The vaper community, particularly online, was considered important in helping to transition to vaping. These online groups were thought to be especially beneficial for new vapers if they did not have existing connections with other vapers.

Also seek advice from local vaping communities such as Facebook groups, this was the most beneficial thing I ever did. They are a wealth of information and so happy to help with any issues you might have and also setting up your device.

This article is protected by copyright. All rights reserved. 
Advice from vapers on switching to vaping

For this participant, online communities offered technical support regarding the use of a device. Others highlighted the emotional support that new vapers can gain from more experienced vapers who had already 'made the switch'. These participants recognised that because transitioning may be difficult, the online community was an important source of support.

"If a new vaper is trying to swap their nicotine delivery from smoking, then there are online resources all over the place which can help and support their journey. It is a major life event to make the switch, so encouraging and supportive environments are invaluable. The knowledge and experience of many add up to not only an alternative, but possibly even a hobby. The generosity and friendship of many of these forums is priceless as well. All ages (adult) are welcome and supported."

This participant highlights that while initial interactions with the vaping community may be about seeking advice and information during the transition period, the community interactions can then expand into supporting other new vapers, or vaping becoming a hobby. The emphasis on 'generosity and friendship' creates an impression that the vaping community cares about the individual and their wellbeing, in contrast to the (implied) isolation of trying to quit tobacco by any other method.

\section{Finding the "right" vaping product}

Many participants made recommendations about the types of devices or the choice of liquid that should be considered by the new user. There was a general consensus that "cigalikes", 
Advice from vapers on switching to vaping

first generation devices that resemble cigarettes in appearance and have disposable cartridges, were not effective compared to second or third generation devices. These latter devices were usually recommended as vapers are able to adjust their device and liquid to get their desired level of nicotine. They are typically bigger, have a tank for refilling liquid and a separate rechargeable battery.

"I would suggest to new vapers that they start with the second generation personal vaporizers, that is the Ego style or pen style batteries together with a refillable/replaceable atomizer tank as the e-cigarette look-alike style will NOT be suitable in assisting them to quit totally."

Battery safety was mentioned by a number of participants as an important factor in relation to NVPs. Most simply suggested that new vapers educate themselves about battery safety, but a handful gave specific advice in this regard. This advice is important as shorting the battery is the source of problems in this area, and there have been publicised cases of exploding batteries - which may contribute to new user caution when thinking about making the switch to NVPs.

"We all know about battery safely. exploding batteries is a rare case, though we dont recommend people buying cheap batteries, in the vaping world when you do buy batteries for a box mod, batteries are married in pairs, they're always together, never separated. they discharged together at the same time and charged together at the same time never putting it in their pocket with keys or coins."

This article is protected by copyright. All rights reserved. 
Advice from vapers on switching to vaping

In relation to liquid, most participants reported using nicotine liquid in their vaporisers, and recommended that those beginning to vape use nicotine. There were two main components of vaping liquid that were discussed: nicotine concentration, and flavour. Most participants did not specifically recommend a particular nicotine concentration, as this was seen to depend on the individual's heaviness of smoking. More commonly, participants encouraged experimentation with different concentrations and flavours to find what was "right" for them.

"I had very little difficulty in switching from smokes to vaping, for me it was a matter of finding the right mod and ejuice flavour as well as nicotine level via a fair bit of trial and error."

In relation to nicotine concentration, there was a common pattern of participants reporting that they started vaping at a higher nicotine level such as 12,18 or 24 milligrams, which they reduced over time to lower levels, or to nicotine-free liquid. Often they recommended this "step down" strategy to others, however the nicotine level at which to start was seen to depend on individual factors, such as their level of cigarette dependence.

\footnotetext{
"I started vaping $24 m g$ and stopped smoking pretty the same day, kept a packet of cigarettes for a week then gave them away. Reduced the nicotine level in the e-liquids i purchased from $24 \mathrm{mg}$ to $18 \mathrm{mg}$ to $12 \mathrm{mg}$ and am now using 6mg. Will go to $3 \mathrm{mg}$ nicotine and after that hope to stop completely."
}

The flavours available for vaping were seen as a major benefit to switching to NVPs; they enhanced the pleasure of vaping, helping make it more enjoyable than smoking cigarettes. 
Advice from vapers on switching to vaping

Cigarettes were often described as having a terrible taste and smell, especially experienced after switching to vaping. Some participants advised against tobacco flavours for this reason, but most recommended that people experiment with different flavours to find ones that they liked.

"I think it is important for a quitting smoker to find a e liquid flavour that they like that is preferably not a tobacco flavour. If you are going to quit, why smell like a cigarette? This is one reason why I would strongly oppose any idea to ban pleasant flavours... I found quitting smoking using e cigarettes to actually be a pleasant experience because of this."

Not surprisingly, a lack of access to nicotine liquid in Australia was described as a significant barrier to vaping. Because nicotine liquid is illegal to use in Australia without a doctor's prescription, and it is illegal for retailers to sell nicotine liquid, those who want to use NVPs as a smoking cessation aid face significant legal and practical challenges in accessing nicotine liquid for their vaporizers. Buying nicotine from a source perceived as safe and trustworthy was seen to be particularly challenging for new users.

"Finding reliable quality assured, sources of nicotine was an issue, it would be better if it was available from certified Australian sources. I am web savvy and have contacts that can 'first hand check out' overseas suppliers, many others cannot do that."

One important difference between cigarettes and NVPs participants identified was the level of organisation required to vape. Because Australians need to import nicotine due to lack of 
Advice from vapers on switching to vaping

local market, ensuring refill liquid is ordered in time before running out was critical. Running out of nicotine was seen to be a significant risk factor for relapsing to smoking. Keeping batteries charged, and having spare batteries was also required.

"The unavailability of nicotine in Australia makes it quite difficult to remain vaping after you have started, Especially when you run out of liquid and have to wait for more to come from overseas. You have to try and find some illegally or start smoking again."

While it was not common, a small number of participants acknowledged that the level of organisation required might make it difficult for older adults who may be less technically minded, or for disadvantaged groups, to switch from cigarettes to NVPs.

\section{Acknowledging an adjustment period}

As described above, more than $90 \%$ of participants had switched from smoking to vaping. Therefore, it is not surprising that most of the advice provided to new vapers assumed that they would be using these devices as a means to quit smoking, rather than to supplement cigarette smoking. There was some disagreement between participants about how easy the user should expect the transition from smoking to vaping to be. Some portrayed it as a very simple process.

"I found the transition from smoking to vaping very easy. It was almost immediate and have had no desire whatsoever to start smoking again, even though I had been a heavy smoker for over 30 years."

This article is protected by copyright. All rights reserved. 
Advice from vapers on switching to vaping

Accounts such as these portrayed vaping as a 'quick and painless' solution to quitting smoking. However, it was also common for these same participants to provide advice on how to adjust to the new behaviours and knowledge required when starting to vape. Some participants detailed their own transition to vaping, which gave insight into the difficulties that new vapers may experience.

"Best advice? Don't push it. The feel, weight and draw of an atomizer is very different to a cigarette..... It took me 2 years to quit totally, which surprised me as quitting was not my intention! Numerous failed attempts, resulting in a rebound increase in ciggie consumption, had always been the result previously. Expect to cough like you did when you first began smoking! But unlike ciggies, this cough disappears entirely."

This participant encourages new users to persist, and used their own experience as an illustration of difficulties others may encounter (feel of the atomizer, nicotine dose, coughing). However, they also contrasted this with the outcomes of switching to vaping - by switching they were able to completely quit smoking without intending to, and their coughing stopped. Other participants mentioned the challenges of adapting to new equipment, and several mentioned that the new vaper should expect the first two to four weeks of vaping to be difficult. Some participants took a blunt approach to this adaptation (e.g. 'you learned to smoke so you can learn to vape'), while others offered suggestions such as dual use (smoking and vaping, and weaning off cigarettes over time), or consciously recreating other habits and routines that they associated with smoking (e.g. 'going outside for my morning coffee and fag etc.'). 
Advice from vapers on switching to vaping

Even those who reported an "easy" transition to vaping often described challenges along the way. As discussed above, many described a process of experimentation to find the "right mix" of device, nicotine and flavour. This required persistence and an initial monetary investment. There was frequent reference to adjusting to using a device that was more "complicated" than smoking cigarettes.

"There are many, small technical obstacles to overcome when you switch to vaping. Even never-smokers have some idea how to light and smoke a cigarette. But beginning vapers may need help and advice, especially less tech-savvy, socially disadvantaged or older smokers. However, the reward for switching can be immense."

"My first advice to a new vaper would be to make them aware that it is not as simple as picking up a vape and puffing away to their heart's content. Vaping requires some learning, and perseverance in the process of finding the best way for them. Vaping is not a quick fix."

Less commonly, participants described a physiological adjustment to vaping, as their body adjusted to not smoking. Addiction to smoking was sometimes described as encompassing more than nicotine addiction, therefore withdrawal symptoms could still be experienced even when the same amount of nicotine is being consumed via vaping.

"When switching to vaping, there is an adjustment for the body. There seems to be more chemicals in cigarettes that are addictive (not just the nicotine), and that the

This article is protected by copyright. All rights reserved. 
Advice from vapers on switching to vaping

body craves when giving up cigarettes. I was unprepared for the cravings that I considered should not be there if nicotine was the only chemical that my body was craving from cigarettes, however perseverance is the key and there still needs to be a desire to give them up for vaping to replace smoking completely."

Other aspects of physiological adjustment that participants mentioned included a longer delay in feeling the effects of nicotine, coughing and dry throat when first using NVPs, and common tobacco withdrawal symptoms such as irritability, cravings, and hunger.

\section{Benefits of vaping}

It was common for respondents who gave advice about persistence to end with a sentiment that it was worth persevering through the adjustment period to vaping:

'Switching ain't easy you got to talk to shops about what's right for you use there [sic] testers to find a flavour or 2 that you like [...] you need support be it from a shop or internet forms or facebook group family friends and I can tell you [vaping] has helped my health [...] I can't stand the smell of tobacco anymore and I owe all this to vaping."

This response illustrates the primary themes of the advice experienced vapers would give to new vapers. The new vaper is encouraged to do their research ('talk to shops about what's right for you'), find a community ('you need support'), and to persist in the transition ('switching ain't easy').

This article is protected by copyright. All rights reserved. 
Advice from vapers on switching to vaping

Many vapers provided personal stories recounting how their own health had improved since they started vaping. They often described the many unsuccessful attempts they had made to quit smoking, despite their awareness that it was damaging their health. NVPs were then presented as a way to achieve noticeably better health.

"I smoked for a very long time and the only way I was able to give up was by vaping. I used to have lung issues due to smoking but now have none thanks to vaping [...] To me that is enough evidence that vaping is better by far than smoking."

For this participant, their experience of improving their health was sufficient evidence for the benefits of vaping. Personal testimony and experience is a powerful form of 'advice'; our participants identified with the difficulties that a new vaper may experience while switching, and drew on their own experience of health benefits to encourage new vapers to persist. While improved health was the primary benefit mentioned by many participants, some participants also stated an additional benefit was saving money.

"My health has improved a lot since I started vaping. I can run around with the kids, I don't feel tired all the time, I have money to be able to pay bills and take the kids out to do things. Vaping has saved my life and improved my health."

The participant quoted above was not the only one to comment that vaping had saved their life. Because they saw vaping as lifesaving for them, participants were often critical of government policy preventing access to nicotine-containing e-liquid.

This article is protected by copyright. All rights reserved. 
Advice from vapers on switching to vaping

"I gave up trying to give up, I resigned myself to a possible early grave to try and control my colitis. Then I came across vaping, I consider a life saving change in my life, I hope I now can live a full life and not die from smoking. I have no plans to quit vaping or to reduce my nicotine level, it helps me control my colitis...I am alarmed at laws our governments want to introduce or have done already. It seems that everyone wants vaping to go away, without considering the benefits it can offer, for me and others."

\section{Discussion}

Research has been conducted exploring how and why Australian vapers start vaping [21], as well as their views on regulation [22]. Asking what advice Australian vapers would give to new vapers reveals what information those seeking information about NVPs might receive, as well as providing a unique insight into Australian vaping practices. This is important as many smokers hear about NVPs from personal interactions with known users, or from information on the internet (much of which will come from current vapers) [23, 24]. Advice from current vapers is likely to be particularly influential in Australia, where information about vaping is not easily available from health organisations or official government sources, and complex state and federal laws restrict the sale and use of NVPs.

The advice that Australian vapers said they would provide to new vapers was very similar to that reported by Russell, Dickson and McKeganey from a large international sample [17]. Russell and colleagues found that advice from current vapers to new vapers centred around

This article is protected by copyright. All rights reserved. 
Advice from vapers on switching to vaping

doing research on NVPs, finding the "right" device/liquid combination, and persisting through an adjustment period [17]. They also wanted to motivate others with personal stories of how their health and hygiene had improved since stopping smoking. The main difference between our findings and Russell et al's is that most of the participants in Russell et al's sample could legally access NVPs. If they wanted to experiment with different nicotine concentrations, they could go to a vape shop and do so. Indeed, vape stores are a major source of technical information and support for vapers in countries where they are legally accessible $[25,26]$. Vape shop staff see themselves as "health advocates" who can assist people to quit smoking $[27,28]$. There is potential to engage vape stores as "frontline consumer educators" or "peer educators" by providing them with the most accurate and up to date information about NVPs $[17,25,26]$. However, because vape stores in Australia cannot sell nicotine liquids, they are less common, and less likely to be visited regularly, so they are less well placed to provide support in Australia while current restrictions on the sale of NVPs remain.

In Australia, because most NVP use is occurring illegally, it is harder to find reputable information and there is more reliance on personal connections with other vapers, a lot of it via online communities. Russell et al wrote of the UK environment prior to 2015:

"In the absence of formal support from public health authorities for smokers to use ecigarettes as an alternative to smoking, and in the face of several health authorities' active discouragement of e-cigarette use as an alternative to smoking, much of the switching that occurred in the United Kingdom prior to 2015 is likely to have involved 
Advice from vapers on switching to vaping

smokers reading about or listening to vapers' personal experiences of switching from smoking to vaping." [17]

Australia remains in this position, making the role of vaping groups and online communities central to the experience of vaping in Australia. Given the wealth and variety of information available about NVPs online, naturalistic studies exploring the strategies people use to find information about NVPs and the resulting information they find would be useful.

While most of the participants in this study had successfully made the transition from smoking to vaping, they acknowledged a number of barriers to making this change including: difficulty sourcing practical and trustworthy information about vaping, concerns about the legality of vaping and importing nicotine liquid, learning the technical skills required to use NVPs, and sourcing trustworthy suppliers of vaping products. Some of these barriers are unique to countries which have banned the sale and/or use of vaping products or nicotine liquids, while others are applicable to all new vapers. Many of these difficulties do not apply to the use of cigarettes, meaning that in Australia, the more harmful nicotine product is the "easy choice" compared to a less harmful option [29].

One important piece of advice to new vapers was to be aware that they may experience an adjustment, or transition, period when starting to replace smoking with vaping. Like any form of smoking cessation, vaping is not a "magic bullet." Acknowledging that there may be an adjustment period, and that this may include a period of dual use of cigarettes and NVPs, may help people to persist in their quit attempt and to transition fully to vaping only. In the public 
arena, a common narrative is of a smoker who tried vaping and never smoked another cigarette, their health improved, and now they dislike cigarettes [30]. These accounts may be true, but the emphasis on a quick and easy transition to vaping may also have a political purpose in a country where access to vaping products containing nicotine is severely limited, and where they are portrayed in a negative light by public health organisations and authorities $[18,31-33]$. However, there is potential that these optimistic accounts may discourage those who find switching more difficult from persisting in their attempt if the transition is not instant and easy. The current analysis presents a more nuanced account around the transition from smoking to vaping. While some participants did portray the process of switching to vaping as easy, it was also common to acknowledge difficulties and to provide strategies that new vapers could use to overcome these.

While it was common to recommend experimentation in relation to nicotine and concentration and flavour, it was clear from our findings that the majority of the participants used third generation tank devices, and this is what many recommended others use. This aligns with evidence from the UK that those using tank devices were more likely to have quit smoking on follow up [7]. However, our participants also identified barriers associated with use of these products, including the learning curve associated with their use and the need to experiment to identify the nicotine concentration and flavour combination that worked for them. Other qualitative research has found that some see tank style devices as "scary" and more complicated than ready to use 'cigalike' products [34]. The simplicity of newer products, particularly JUUL and similar pod-like systems, address this barrier to use, and 
Advice from vapers on switching to vaping

have likely contributed to their commercial success in the U.S. and concerns of an 'epidemic' in vaping amongst young people $[35,36]$.

It was common for current vapers to also stress the importance of finding appealing flavours in helping them to switch from smoking. This is consistent with other studies with vapers that find that most use flavoured NVPs [37]. One online study found that vapers reported using them because they came in appealing flavours (60.2\%) and they liked experimenting with flavours $(59.5 \%)$ [38]. Another found that $85.4 \%$ of experienced vapers found variety of flavour choices important [39]. However, the availability and promotion of appealing flavours is a current point of contention in the tobacco control community. There are concerns that flavours are being used to appeal to young people, particularly candy or fruit flavours. The Commissioner of the FDA recently stated that they "may take steps to curtail the marketing and selling of flavored products" [36]. The difficulty in regulating flavourings aimed at curbing youth use of NVPs, is that it may also make vaping less appealing to adults, such as the participants in this study, who are smokers using NVPs to quit smoking and prevent relapsing to smoking [40].

A limitation of this study is that this advice is from a subsection of vapers who have successfully integrated vaping into their daily lives. While some were still smoking cigarettes, this was occasional. Therefore, this study does not provide the perspectives of individuals who may have tried, but then given up on vaping - either due to lack of success in quitting tobacco cigarettes, or a dislike of NVPs. It is not possible to speculate what their 
advice to new vapers may have been, and any useful lessons that could be taken from their experiences. Further, and in common with most studies conducted with vapers, those who took part and wrote further comments in the survey were often enthusiastic advocates for vaping. Their views and advice over-represents members of the vaping community that they are encouraging new vapers to engage with. In addition, whether the "new vaper" was an existing smoker, an ex-smoker or a non-smoker was not mentioned in the question asked of participants. However, the responses were typically directed at smokers who might be interested in quitting smoking.

Our research demonstrates that engaging constructively with the vaping community can provide useful insights into factors that impede and assist smokers to transition from smoking to vaping in Australia, especially in the context of varying and complex laws governing use of vaping devices across Australian states and territories [2]. More co-operation between the Australian public health and vaping communities could be very beneficial to public health.

\section{Acknowledgements}

We would like to thank the participants who responded to the survey. This project is funded by the National Health and Medical Research Council of Australia (GNT1106451). Associate Professor Coral Gartner was supported by a National Health and Medical Research Council Career Development Fellowship (GNT1061978). Thanks to Dr Cheneal Puljevic for helpful comments on the manuscript. 
Advice from vapers on switching to vaping

\section{$\underline{\text { References }}$}

[1] West R, Beard E, Brown J. Trends in electronic cigarette use in England; 2016. Available from: http://www.smokinginengland.info/sts-documents/ [Date accessed 2 January 2019].

[2] Douglas H, Hall W, Gartner C. E-cigarettes and the law in Australia. Aus Fam Physician 2015;44:415-8.

[3] Therapeutic Goods Administration. Electronic cigarettes. Available from: https://www.tga.gov.au/community-qa/electronic-cigarettes [Date accessed 2 January 2019].

[4] Australian Institute of Health and Welfare. National Drug Strategy Household Survey 2016: Detailed Findings; 2017. Available from:

https://www.aihw.gov.au/reports/illicit-use-of-drugs/ndshs-2016detailed/contents/table-of-contents [Date accessed 2 January 2019].

[5] Hartmann-Boyce J, McRobbie H, Bullen C, Begh R, Stead LF, Hajek P. Electronic cigarettes for smoking cessation. Cochrane Database Syst Rev 2016;9:CD010216.

[6] Brown J, Beard E, Kotz D, Michie S, West R. Real-world effectiveness of e-cigarettes when used to aid smoking cessation: a cross-sectional population study. Addiction 2014;109:1531-40.

[7] Hitchman SC, Brose LS, Brown J, Robson D, McNeill A. Associations between ecigarette type, frequency of use, and quitting smoking: Findings from a longitudinal online panel survey in Great Britain. Nicotine Tob Res 2015;17:1187-94.

This article is protected by copyright. All rights reserved. 
[8] Villanti Andrea C, Feirman Shari P, Niaura Raymond S, Pearson Jennifer L, Glasser Allison M, Collins Lauren K, et al. How do we determine the impact of e-cigarettes on cigarette smoking cessation or reduction? Review and recommendations for answering the research question with scientific rigor. Addiction 2017;113:391-404.

[9] Yong H-H, Hitchman SC, Cummings KM, Borland R, Gravely SML, McNeill A, et al. Does the regulatory environment for e-cigarettes influence the effectiveness of ecigarettes for smoking cessation?: Longitudinal findings from the ITC Four Country Survey. Nicotine Tob Res 2017;19:1268-76.

[10] Farsalinos KE, Polosa R. Safety evaluation and risk assessment of electronic cigarettes as tobacco cigarette substitutes: a systematic review. Ther Adv Drug Saf 2014;5:67-86.

[11] McNeill A, Brose L, Calder R, Bauld L, Robson D. Evidence review of e-cigarette and heated tobacco products 2018: A report commissioned by Public Health England. London: Public Health England; 2018. Available at:

https://www.gov.uk/government/uploads/system/uploads/attachment_data/file/684963 /Evidence_review_of_e-cigarettes_and_heated_tobacco_products_2018.pdf [Date accessed 2 January 2019].

[12] Barbeau AM, Burda J, Siegel M. Perceived efficacy of e-cigarettes versus nicotine replacement therapy among successful e-cigarette users: A qualitative approach. Addict Sci Clin Pract2013;8(1):5.

[13] Rooke C, Cunningham-Burley S, Amos A. Smokers' and ex-smokers' understanding of electronic cigarettes: A qualitative study. Tob Control 2015;25:e60-e66.

This article is protected by copyright. All rights reserved. 
Advice from vapers on switching to vaping

[14] UK National Health Service. 2017. Available at: https://www.nhs.uk/oneyou/foryour-body/quit-smoking/using-e-cigarettes-vapes-to-quit-smoking/ [Date accessed 2 January 2019].

[15] Committee of Advertising Practice. E-cigarettes: Health Claims and Public health Advertisements. London; 2017. Available at: https://www.asa.org.uk/asset/710B71467B3C-4047-95C3E89268FAAE4A.5D38D4B3-0F1C-440D-A0B8894BF588C41D/

[Date accessed 2 January 2019].

[16] Yong H-H, Borland R, Balmford J, Hitchman SC, Cummings KM, Driezen P, et al. Prevalence and correlates of the belief that electronic cigarettes are a lot less harmful than conventional cigarettes under the different regulatory environments of Australia and the United Kingdom. Nicotine Tob Res 2016;19:258-63.

[17] Russell C, Dickson T, McKeganey N. Advice from former-smoking e-cigarette users to current smokers on how to use e-cigarettes as part of an attempt to quit smoking. Nicotine Tob Res 2017;20:977-84.

[18] Cancer Council Australia. Position statement - Electronic cigarettes; 2016. Available at: http://wiki.cancer.org.au/policy/Position_statement_-_Electronic_cigarettes [Date accessed 2 January 2019].

[19] International Tobacco Control Policy Evaluation Project. Methods of the International Tobacco Control Policy Evaluation Project. 2018. Available at: https://www.itcproject.org/methods [Date accessed 2 January 2019].

[20] Braun V, Clarke V. Using thematic analysis in psychology. Qual Res Psychol 2006;3:77-101.

This article is protected by copyright. All rights reserved. 
Advice from vapers on switching to vaping

[21] Adkison SE, O'Connor RJ, Bansal-Travers M, Hyland A, Borland R, Yong H-H, et al. Electronic nicotine delivery systems: International Tobacco Control Four-Country Survey. Am J Prev Med 2013;44:207-15.

[22] Fraser D, Weier M, Keane H, Gartner C. Vapers' perspectives on electronic cigarette regulation in Australia. Int J Drug Policy 2015;26:589-94.

[23] Pepper JK, Emery SL, Ribisl KM, Brewer NT. How U.S. adults find out about electronic cigarettes: Implications for public health messages. Nicotine Tob Res 2014;16:1140-4.

[24] Wackowski OA, Bover Manderski MT, Delnevo CD. Smokers' source of e-cigarette awareness and risk information. Prev Med Rep 2015;2:906-10.

[25] Cheney MK, Gowin M, Wann TF. Vapor store owner beliefs and messages to customers. Nicotine Tob Res 2016;18:694-99.

[26] Polosa R, Caponnetto P, Cibella F, Le-Houezec J. Quit and smoking reduction rates in vape shop consumers: A prospective 12-month survey. Int J Environ Res Public Health 2015;12:3428-38.

[27] Hart JL, Walker KL, Sears CG, Lee AS, Smith C, Siu A, et al. Vape shop employees: Public health advocates? Tob Prev Cessation 2016;2(Suppl):

[28] Nayak P, Kemp CB, Redmon P. A qualitative study of vape shop operators' perceptions of risks and benefits of e-cigarette use and attitude toward their potential regulation by the US Food and Drug Administration. Prev Chronic Dis 2016;13:E68.

[29] Ashe M, Graff S, Spector C. Changing places: Policies to make a healthy choice the easy choice. Public Health 2011;125:889-95.

This article is protected by copyright. All rights reserved. 
Advice from vapers on switching to vaping

[30] Horn A. Support grows to legalise e-cigarettes in Australia. ABC News. 2017. Available from: http://www.abc.net.au/news/2017-07-27/to-quit-smoking-i-had-tobecome-a-criminal/8746676 [Date accessed 30 October 2018]. [31]

[31] Australian Government Department of Health. Principles that underpin the current policy and regulatory approach to electronic cigarettes (E-cigarettes) in Australia. Available at:

http://www.health.gov.au/internet/main/publishing.nsf/Content/principles-underpincurrent-policy-regulatory-approach-electroniccigarettes-eeCigarettes-australia [Date accessed 2 January 2019].

[32] National Health and Medical Research Council. NHMRC CEO Statement: Electronic Cigarettes (E-cigarettes). 2017. Available at:

https://www.nhmrc.gov.au/_files_nhmrc/file/publications/17072_nhmrc__electronic_cigarettes-web_final.pdf [Date accessed 2 January 2019].

[33] Queensland Health. Electronic cigarettes. 2017. Available at: https://www.health.qld.gov.au/public-health/topics/atod/tobacco-laws/electroniccigarettes [Date accessed 2 January 2019].

[34] Wadsworth E, Neale J, McNeill A, Hitchman CS. How and why do smokers start using e-cigarettes? Qualitative study of vapers in London, UK. Int J Environ Res Public Health 2016;13(7).

[35] Barrington-Trimis JL, Leventhal AM. Adolescents' use of “Pod Mod" e-cigarettes Urgent concerns. NEJM 2018;379:1099-102.

This article is protected by copyright. All rights reserved. 
Advice from vapers on switching to vaping

[36] Gottlieb S. Statement from FDA Commissioner Scott Gittlieb on new steps to address epidemic of youth e-cigarette use. U.S. Food and Drug Administration; 2018. Available at:

https://www.fda.gov/NewsEvents/Newsroom/PressAnnouncements/ucm620185.htm

[Date accessed 2 January 2019].

[37] Harrell MB, Weaver SR, Loukas A, Creamer M, Marti CN, Jackson CD, et al. Flavored e-cigarette use: Characterizing youth, young adult, and adult users. Prev Med Rep 2017;5:33-40.

[38] Berg CJ. Preferred flavors and reasons for e-cigarette use and discontinued use among never, current, and former smokers. Int J Public Health 2016;61:225-36.

[39] Yingst JM, Veldheer S, Hrabovsky S, Nichols TT, Wilson SJ, Foulds J. Factors associated with electronic cigarette users' device preferences and transition from first generation to advanced generation devices. Nicotine Tob Res 2015;17:1242-6.

[40] Farsalinos K, Romagna G, Tsiapras D, Kyrzopoulos S, Spyrou A, Voudris V. Impact of flavour variability on electronic cigarette use experience: An internet survey. Int J Environ Res Public Health 2013;10:7272-82.

This article is protected by copyright. All rights reserved. 
Advice from vapers on switching to vaping

Table 1: Respondent characteristics

\begin{tabular}{|c|l|}
\hline Female & $26 \%$ \\
\hline Mean age (SD) & 43 (SD 12) \\
\hline Smoking status & \\
\hline Occasional (<weekly) & $8 \%$ \\
\hline Quit in last two years & $56 \%$ \\
\hline Quit more than two years ago & $37 \%$ \\
\hline Duration of daily vaping & \\
\hline d3 months & $11 \%$ \\
\hline $4-12$ months & $25 \%$ \\
\hline $1-2$ years & $25 \%$ \\
\hline$>2$ years & $40 \%$ \\
\hline Speak English only at home & $92 \%$ \\
\hline Aboriginal or Torres Strait Islander & $2 \%$ \\
\hline Education* & $10 \%$ \\
\hline Did not complete high school & $37 \%$ \\
\hline Completed high school & \\
\hline Technical or TAFE certificate & \\
\hline Some university education & \\
\hline
\end{tabular}

$* 2 \%$ refused to answer this item.

This article is protected by copyright. All rights reserved. 


\section{University Library}

\section{- M M N E R VA A gateway to Melbourne's research publications}

Minerva Access is the Institutional Repository of The University of Melbourne

Author/s:

Morphett, K;Weier, M;Borland, R;Yong, H-H;Gartner, C

Title:

Barriers and facilitators to switching from smoking to vaping: Advice from vapers

Date:

2019-03-01

Citation:

Morphett, K., Weier, M., Borland, R., Yong, H. -H. \& Gartner, C. (2019). Barriers and

facilitators to switching from smoking to vaping: Advice from vapers. DRUG AND ALCOHOL REVIEW, 38 (3), pp.234-243. https://doi.org/10.1111/dar.12907.

Persistent Link:

http://hdl.handle.net/11343/285436 